\title{
Effect of Chronic Aluminum Administration on Affective and Cognitive Behavior in Male and Female Rats
}

\author{
Oussama Zghari ${ }^{*}$, Ayoub Rezqaoui ${ }^{1}$, Sihame Ouakki ${ }^{1}$, Mouloud Lamtai ${ }^{1}$, Jihane Chaibat ${ }^{1}$, \\ Abdelhalem Mesfioui' ${ }^{1}$, Aboubaker El Hessni' ${ }^{1}$, El-Housseine Rifi ${ }^{2}$, Azzouz Essamri ${ }^{3}$, Ali Ouichou ${ }^{1}$ \\ ${ }^{1}$ Unit of Nervous and Endocrine Physiology, Laboratory of Genetics, Neuroendocrinology and Biotechnology, University Ibn \\ Tofail, Kenitra, Morocco \\ ${ }^{2}$ Laboratory of Synthesis Organic and Extraction Processes, Department of Chemistry, Faculty of Science, University Ibn Tofail, \\ Kenitra, Morocco \\ ${ }^{3}$ Laboratory of Agro-Resources and Process Engineering, Faculty of Science, University Ibn Tofail, Kenitra, Morocco \\ Email: ${ }^{\star}$ zghari.oussama.91@gmail.com
}

How to cite this paper: Zghari, O., Rezqaoui, A., Ouakki, S., Lamtai, M., Chaibat, J., Mesfioui, A., El Hessni, A., Rifi, E.-H., Essamri, A. and Ouichou, A. (2018) Effect of Chronic Aluminum Administration on Affective and Cognitive Behavior in Male and Female Rats. Journal of Behavioral and Brain Science, 8, 179-196.

https://doi.org/10.4236/jbbs.2018.84012

Received: January 17, 2018

Accepted: April 23, 2018

Published: April 26, 2018

Copyright $\odot 2018$ by authors and Scientific Research Publishing Inc. This work is licensed under the Creative Commons Attribution International License (CC BY 4.0).

http://creativecommons.org/licenses/by/4.0/

\begin{abstract}
In this study, we investigated the effect of chronic exposure of low doses of Aluminum on affective and cognitive disorders in male and female rats. Twenty-five rats for each gender are used and the treatment carried out for 8 weeks. Animals received distilled water for control or an intraperitoneal injection of different doses of Aluminum: 0.125, 0.25, 0.5 and $1 \mathrm{mg} / \mathrm{kg}$. Behavioral performance is measured in various tests mainly the Open Field, Elevated Plus Maze, Force Swimming Test, Morris Water Maze, Y-maze and Object Recognition Test. $\mathrm{Al}$ exerts anxiogenic properties and depressive effect. The effect begins at $0.25 \mathrm{mg} / \mathrm{kg}$ to reach a maximum at $1 \mathrm{mg} / \mathrm{kg}$. In addition, chronic exposure to Aluminum causes cognitive disorders characterized by affection of memory and influence spatial learning performance. The effect of Aluminum on working memory is effective just at $1 \mathrm{mg} / \mathrm{kg}$, while the effect on spatial learning performance begins at $0.25 \mathrm{mg} / \mathrm{kg}$ to reach a maximum at 1 $\mathrm{mg} / \mathrm{kg}$. In conclusion, Aluminum enhances anxiety and depression parameters and cognitive disorders characterized by the affection of memory and spatial learning performance.
\end{abstract}

\section{Keywords}

Aluminum, Anxiety, Depression, Memory, Behavioral Tests, Wistar Rat

\section{Introduction}

Aluminum (Al) is the third most abundant element and the most common metal 
in the earth's crust; it is ubiquitous in the environment and is extensively used in daily life that provides easy exposure to human to this toxic metal mainly via air, food and water. It has been shown that $\mathrm{Al}$ can reach systemic circulation, and rapidly transferred to the brain across the blood brain barrier (BBB) via specific high affinity receptors for transferrin via different routes and accumulates in various tissues such as brain, bone, liver and kidney [1].

Although the relationship between high levels of $\mathrm{Al}$ and increased risk of a number of neurodegenerative disorders including Alzheimer's disease (AD), Parkinson's disease (PD) [2] and affective and cognitive troubles has been suggested, the exact mechanism of $\mathrm{Al}$ implication in these functions was not clearly established. However, it seems that in some brain region such as hippocampus and frontal cortex, $\mathrm{Al}$ causes disruption of homeostasis of same metals, oxidative stress, cell mediated toxicity, apoptosis, inflammatory, gene expression and neurofibrillary tangle formation [3]. Also, $\mathrm{Al}$ can interfere with cellular and metabolic processes, including glutamatergic, dopaminergic neurotransmission, phosphoinositide signal transduction pathway [4]. Experimental studies in rodents have also indicated that $\mathrm{Al}$ disturbed cholinergic system [5], caused neurobehavioral alterations [6] and mitochondrial oxidative stress.

The objective of this study was to determine the effect of chronic administration of $\mathrm{Al}$ on affective and cognitive disorders in Wistar rats.

\section{Material \& Methods}

\subsection{Animals and Experimental Conditions}

This study was performed on male and female Wistar rats (from University Ibn Tofail) aged 8 to 9 weeks, initially weighing $120 \pm 20 \mathrm{~g}$ and were grouped by five in cages (LWH: 36/20/15 cm). Rats were maintained under LD 12/12 and temperature of $21^{\circ} \mathrm{C} \pm 1^{\circ} \mathrm{C}$. Water and food were provided ad libitum. All experimental procedures were approved by the University Ethics Committee for Animal Experiments.

Five groups of 5 animals for each sex were constituted as follows:

1) 1st group: rats control receiving daily an intraperitoneal injection of distilled water.

2) 2nd group: rats receiving daily a dose of $0.125 \mathrm{mg} / \mathrm{kg}$ of Al as $\mathrm{AlCl}_{3}$.

3) 3rd group: rats receiving daily a dose of $0.25 \mathrm{mg} / \mathrm{kg}$ of $\mathrm{Al}$ as $\mathrm{AlCl}_{3}$.

4) 4th group: rats receiving daily a dose of $0.5 \mathrm{mg} / \mathrm{kg}$ of Al as $\mathrm{AlCl}_{3}$.

5) 5th group: rats receiving daily $1 \mathrm{mg} / \mathrm{kg}$ of $\mathrm{Al}$ as $\mathrm{AlCl}_{3}$.

Distilled water and $\mathrm{AlCl}_{3}$ (SIGMA-ALDRICH) were injected intraperitoneally at the rate of one injection/day between (16:00 and 17:00) during 8 weeks.

\subsection{Neurobehavioral Tests}

\subsubsection{Anxiety-Like Measurement}

Open Field Test: The OFT used in this study is conforming to that previously reported [7]. The maze adopted is made of wood $(100 \mathrm{~cm} \times 100 \mathrm{~cm})$ enclosed 
with $40 \mathrm{~cm}$ high walls and placed under strong illumination $(100 \mathrm{~W}, 2 \mathrm{~m}$ above the apparatus). The area was divided into 25 squares $(20 \mathrm{~cm} \times 20 \mathrm{~cm})$, defined as 9 central and 16 peripheral squares. At the beginning of the $10 \mathrm{~min}$ test, the animal was placed in the centre of the apparatus and its behavior was videotaped for subsequent analysis. The quantified parameters were the time spent in the center of the area (TCA) and the number of returns to the center (NRC). Central perimeter residence time is used as a measure of anxiety. The number of returns to the central area is also an indicator of the emotional reactivity. The central area of a novel environment is anxiogenic and aversive and the behavioral inhibition appears therefore as an avoidance behavior towards the central zone of the OFT. Number of total squares (NTS) represents Locomotors activity. The apparatus was cleaned between each examination using 70\% ethyl alcohol.

Test of the Elevated Plus Maze (EPM): The EPM is an ethological model of anxiety in rodents provoked by the novelty and repulsion as a result of elevation and illumination of the maze [8]. This test is based on the creation of a conflict between the exploratory drive of the rat and its innate fear of open and exposed areas; it has been validated for the detection of emotional responses to anxiogenic and anxiolytic substances. Thus, increased open-arms exploration indicates reduced anxiety-related behavior. The EPM consists of a wooden plus-shaped platform elevated $70 \mathrm{~cm}$ above the floor. Two of the opposing arms $(50 \mathrm{~cm} \times 10$ $\mathrm{cm}$ ) are closed by $40 \mathrm{~cm}$ high side and end walls, having an open roof. In order to avoid fall, the other two arms (open arms) were surrounded by $0.5 \mathrm{~cm}$ high edge, the four arms had at their intersection a central platform $(10 \mathrm{~cm} \times 10 \mathrm{~cm})$. A 100-W lamp was placed exactly over the central platform. At the beginning of the test, the rats were placed on the central area of the maze facing an open arm. The following parameters of anxiety-related behavior were measured during the 5 min testing period: 1) entries into open arms (EOA), 2) time spent on the open arms (TOA), and 3) number of full entries into the arms (TAE). Decreased anxiety-like behavior is illustrated by a significant statistical increase of parameters in open arms (time and/or entries). The total number of the entries into all arms provides general hyperactivity. To eliminate any lingering olfactory cues, the apparatus was cleaned between each examination using $70 \%$ ethyl alcohol.

\subsubsection{Depression-Like Measurement in Forced Swimming Test (FST)}

The FST is an excellent maze used to assess the depressive-like behavior [9]. Swimming sessions were conducted by placing the rat in individual glass cylinders (height $=50 \mathrm{~cm}$; diameter $=30 \mathrm{~cm}$ ) containing $30 \mathrm{~cm}$ of water at $\left(23^{\circ} \mathrm{C} \pm\right.$ $2^{\circ} \mathrm{C}$ ). During the session, rats were forced to swim for $5 \mathrm{~min}$ and the duration of immobility was measured. The latency to the first bout of immobility was also recorded starting immediately after placing the rats in the cylinder. A rat was considered immobile when it ceased all active behaviors (i.e. struggling, swimming and jumping) and remained passively floating or making minimal movements necessary to maintain the nostrils above water. High percent time floating is interpreted as an increased depressive-like response [9] [10]. 


\subsubsection{Cognitive Measurement}

Y-maze test: Spatial working memory was assessed by using the Y-maze spontaneous alternation test, as previously described [11]. Each mouse was placed in the center of the Y-maze and was free to explore the arena for $8 \mathrm{~min}$. The number of entries was counted per rat: an entry required that both hind paws of the animal had to be placed completely inside the arm. A rat would be making a triad when it visited all 3 arms consecutively. Between sessions, the maze was cleaned thoroughly with a $7 \%$ ethanol solution. As a measure for working memory, the percentage of alternations that the rat made was calculated, being the number of triads divided by the maximum possible alternations (i.e. the total number of entries minus 2$) \times 100$. If a rat scored significantly above $50 \%$ alternations (the chance level for choosing the unfamiliar arm), this was indicative of functional working memory.

Object recognition test: The object recognition test is particularly useful for studying rodent declarative memory because it uses their natural preference for a new object in relation to a familiar object. The object recognition test was performed according to the method described previously [12] with certain modifications. The experiments were carried out in a black open field box measuring $50 \mathrm{~cm} \times 25 \mathrm{~cm} \times 50 \mathrm{~cm}$.

In most protocols, the test is divided into 3 phases (session):

1) Familiarization session (the animal is free to explore the space with no objects present), the habituation time is 5 minutes in our experience (the time varies between 3 and $10 \mathrm{~min}$ );

2) Training session (the animal is in the presence of two similar objects);

3) Test session (the experimenter introduces a new object instead of a familiar object).

On the test day, rats were placed in the test box, and after a 5-min habituation period, two objects were introduced in two corners (approximately $30 \mathrm{~cm}$ apart from each other). The time spent exploring each object was recorded during the subsequent 5 min period (defined as the training session). Then the rats were returned to their home cage. After a waiting period of $120 \mathrm{~min}$ ( 2 hours), the rats were placed in the test box once again, and 5 min later objects were reintroduced, in which one of the familiar object used in the previous training session was replaced with a novel object (we repeat the test session after 24 hours). The time spent exploring each object was recorded during the subsequent 5 min period (defined as the test session). The animals were regarded to be exploring when they were facing, sniffing or biting the object. The test box and objects were cleaned with $70 \%$ of ethanol between trials. A recognition index was used to measure memory preference $(\mathrm{RI}=[\mathrm{TN} /(\mathrm{TN}+\mathrm{TF})] \times 100$ with $\mathrm{TN}=$ time spent on the novel object and TF = time spent on the familiar object).

Morris Water Maze Test: The water maze [13] consisted of a circular polypropylene pool $(110 \mathrm{~cm}$ in diameter and $20 \mathrm{~cm}$ high) that was filled to a depth of $14 \mathrm{~cm}$ with room-temperature tap water $\left(22^{\circ} \mathrm{C}\right)$. The water was made opaque 
with the addition of $500 \mathrm{ml}$ of nontoxic white liquid tempera paint to ensure camouflage of the escape platform. The escape platform was constructed from a Plexiglas cylinder ( $13.75 \mathrm{~cm}$ high, $9 \mathrm{~cm}$ in diameter), which was painted white. The water level was $0.5 \mathrm{~cm}$ above the platform, making it invisible. The platform had a red top and colorful flag that were added for visible platform trials. The water maze was located in a room $(5.2 \mathrm{~m} \times 2.4 \mathrm{~m})$ with posters and furniture around the walls, which served as extra-maze visual cues. During testing, the room was dimly lit with diffuse white light (30 lx). Rats were tested in the Morris water maze in four phases: acquisition, reversal, probe trial and visible platform trial [14]. During acquisition (4 trials/day for 4 days), rats were trained to swim to a hidden platform that was located in the Northeast quadrant. Each rat was removed from its holding cage using a plastic container and released from a randomly assigned start location (East, North, South or West). If the rat did not find the platform within $60 \mathrm{~s}$, it was guided to the platform and allowed to stay on it for approximately $10 \mathrm{~s}$. The inter-trial interval was approximately $5 \mathrm{~min}$. On day 5 , rats were tested for spatial memory in a $60 \mathrm{~s}$ probe trial with no platform present and after 2 hours rats were tested (four trials) using a visible platform, which was placed in the Northwest quadrant [15].

\subsection{Statistical Analysis}

Behavioral data and biochemical parameters were analyzed by two-way ANOVA using SPSS version 22. Post hoc comparisons were made using the Tukey's test. ANOVA repeat measures were used for the Morris water maze test. All data are expressed as the means \pm standard error of the means (S.E.M). In order to estimate the gender effect, we expressed the results for each sex as a percentage of the basal level (\% BL) represented by the respective control and considered as being $100 \%$. Differences were considered significant when $p<0.05$, very significant when $p<0.01$ and highly significant when $p<0.001$.

\section{Results}

\subsection{Effect of Al on the Levels of Anxiety-Like Measured in the OFT}

1) Time spent in the central area (TCA) (Figure 1(a)):

The TCA presented in Figure 1(a) is significantly affected by the treatment factor $(p<0.001)$. In males, $\mathrm{Al}$ affects significantly the TCA parameter only at 0.25 and $1 \mathrm{mg} / \mathrm{kg}$ compared to the control group (Cont/Al-0.25: $p<0.05$; Cont/Al-1: $p<0.001), \mathrm{Al}$ induced mean average decrease of $22.5 \% \pm 7 \%, 27.9 \%$ $\pm 4 \%, 18.6 \% \pm 1.7 \%$ and $48.1 \% \pm 6.3 \%$ at doses of $0.125,0.25,0.5$ and $1 \mathrm{mg} / \mathrm{kg}$ respectively. The groups treated with $0.125,0.25$ or $0.5 \mathrm{mg} / \mathrm{kg}$ spend almost the same time in the central area. There is a significant difference between Al-0.125 and Al-1 and between Al-0.5 and Al-1 groups (Al-0.125/Al-1: $p<0.05$; Al-0.5/Al-1: $p<0.01)$. In females, $\mathrm{Al}$ affects TCA in dose-dependent manner between 0.125 and $1 \mathrm{mg} / \mathrm{kg}$. The rats treated with $1,0.5$, and $0.25 \mathrm{mg} / \mathrm{kg}$ of $\mathrm{Al}$, 


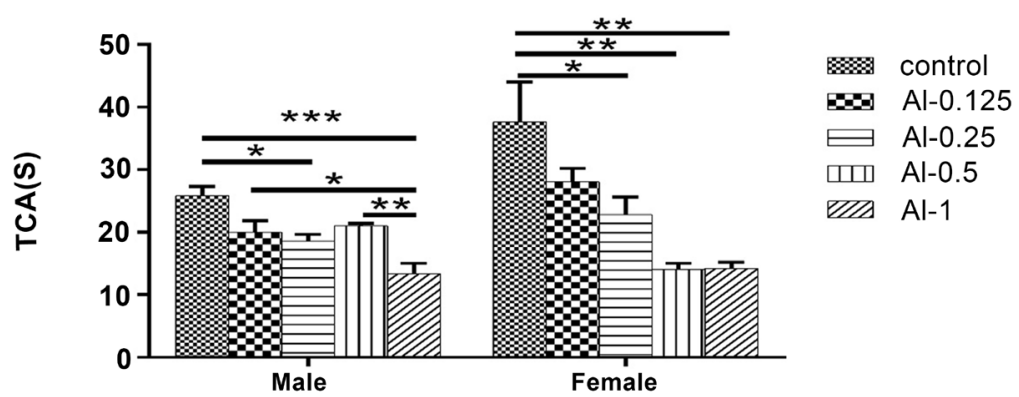

(a)
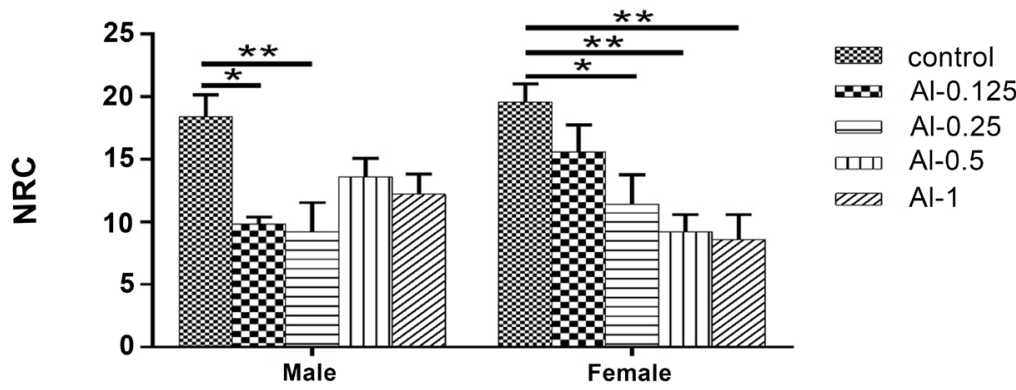

(b)
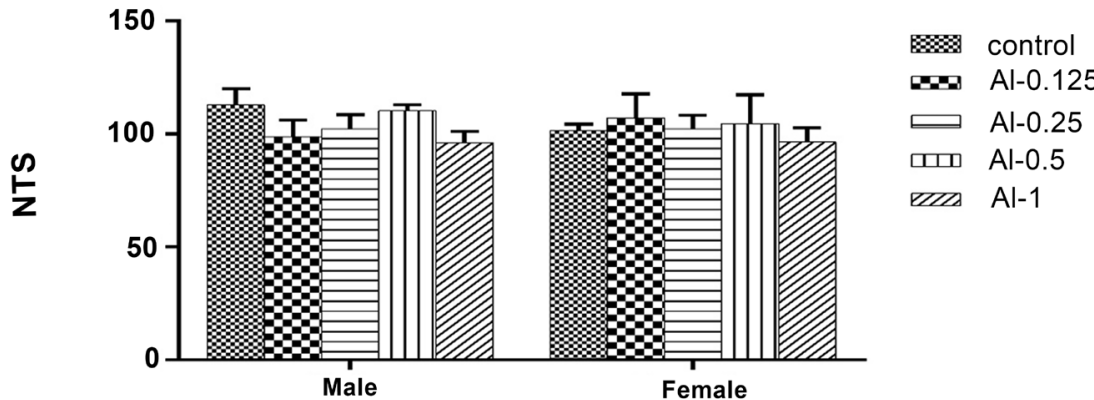

(c)

Figure 1. (a) Total amount time spent in the center (TCA); (b) Number of return into center (NRC); and (c) Number of total squares (NTS) in the OFT by rats after 8 weeks of treatment with different doses of Al. Results are expressed as mean \pm SEM. The significance level is $0.05 .{ }^{*} p<0.05,{ }^{* *} p<0.01,{ }^{* *} p<0.001$.

spend significantly less time in the central area compared to the control (Cont/Al-0.25: $p<0.05$; Cont/Al-0.5: $p<0.01$ and Cont/Al-1: $\mathrm{p}<0.01$ ). Al induced mean average decrease of $25.5 \% \pm 5.9 \%, 39.4 \% \pm 7.6 \%, 62.8 \% \pm 2.7 \%$ and $62.2 \% \pm 2.7 \%$ at doses of $0.125,0.25,0.5$ and $1 \mathrm{mg} / \mathrm{kg}$ respectively. No difference was noted between Al-0.125/Al-0.25, Al-0.25/Al-0.5 and Al-0.5/Al-1 groups ( $p>$ 0.05).

The sex effect was more visible when considering the relative comparison (TCA\% BL) between respective treated $\mathrm{Al}$ groups in males and females. Indeed, the females of the groups Al-0.5 and Al-1 showed a TCA significantly lower compared to males of similar groups $(p<0.001$ and $p<0.05)$.

2) Number of Returns to the Center (NRC) (Figure 1(b)):

NRC Parameter presented in Figure 1 (b) was significantly affected by Al 
treatment $(p<0.001)$ and no effect of sex $(p>0.05)$ was noted. In male, significant decrease of NRC was observed in groups treated with 0.125 and $0.25 \mathrm{mg} / \mathrm{kg}$ compared to the control (Cont/Al-0.125: $p<0.05$ ); Cont/Al-0.25: $p<0.01$ ). No significant difference was found for the groups treated with 0.5 and $1 \mathrm{mg} / \mathrm{kg}$ despite the observed decrease of NRC (Cont/Al-0.5: $p>0.05$; Cont/Al-1: $p>0.05$ ). In addition, no difference was noted between Al-0.125/Al-0.25, Al-0.25/Al-0.5 and Al-0.5/Al-1 groups ( $p>0.05)$.

In females, $\mathrm{Al}$ decreases the NRC in dose-dependent manner. Except at dose of $0.125 \mathrm{mg} / \mathrm{kg}(p>0.05), \mathrm{Al}$ significantly decreases the NRC compared to the control at all other doses (Cont/Al-0.25: $p<0.05$; Cont/Al-0.5: $p<0.01$ and Cont/Al-1: $p<0.01$ ). No difference was noted between Al-0.125/Al-0.25, Al-0.25/Al-0.5 and Al-0.5/Al-1 groups ( $p>0.05)$.

3) Number of total squares (NTS) (Figure 1(c)):

Locomotors activity represented by NTS in Figure 1(c) was unaffected by any treatment. The values of all groups were comparable.

\subsection{Effect of Al on Anxiety Levels Measured in Elevated Plus Maze (Test EPM)}

\section{1) Time Spent in Open Arms (TOA) (Figure 2(a)):}

Statistical analysis showed that TOA presented in Figure 2(a) was significantly affected by Al treatment $(p<0.001)$ and no effect of sex $(p>0.05)$ was noted. In males, all groups treated with different doses of $\mathrm{Al}(0.125,0.25,0.5$ and $1 \mathrm{mg} / \mathrm{kg}$ ) spend less time in open arms compared to control, but with significant difference for Al-0, 5 and Al-1 $(p<0.01)$. No difference was noted between Al-0.125/Al-0.25, Al-0.25/Al-0.5 and Al-0.5/Al-1 groups $(p>0.05)$. In females, $\mathrm{Al}$ decrease the TOA parameter; its effect beginning at $0.25 \mathrm{mg} / \mathrm{kg}$ since 0.125 $\mathrm{mg} / \mathrm{kg} \mathrm{Al}$ was not effective $(p>0.05)$. The effects of $\mathrm{Al}$ at $0.25,0.5$ and $1 \mathrm{mg} / \mathrm{kg}$ are significantly lower compared to the control (Cont/Al-0.25: $p<0.05$; Cont/Al-0.5: $p<0.01$ and Cont/Al-1: $p<0.01)$. No significant difference was observed with comparing different treated $\mathrm{Al}$ groups $(p>0.05)$.

2) Entry to Open Arms (EOA) (Figure 2(b)):

Figure 2(b) shows that the treatment factor significantly affected the EOA ( $p$ $<0.001)$. In males, $\mathrm{Al}$ decrease significantly the EOA parameter only at $1 \mathrm{mg} / \mathrm{kg}$ compared with the control (cont/Al-1: $p<0.01$ ); all other doses remaining ineffective (Cont/Al-0.125; Cont/Al-0.25 and Cont/Al-0.5: $p>0.05$ ). Al induced mean average decrease of $33.3 \% \pm 5.8 \%, 13.3 \% \pm 11.1 \%, 26.7 \% \pm 11.3 \%$ and $50 \%$ $\pm 9.1 \%$ at doses of $0.125,0.25,0.5$ and $1 \mathrm{mg} / \mathrm{kg}$ respectively. No significant difference was observed with comparing different treated $\mathrm{Al}$ groups $(p>0.05)$. In females, at doses of $0.25,0.5$ and $1 \mathrm{mg} / \mathrm{kg}, \mathrm{Al}$ decreases the EBO parameter in comparison with the control (Cont/Al-0.25: $p<0.05$; Cont/Al-0.5: $p<0.01$ and Cont/Al-1: $p<0.01)$. Whereas at $0.125 \mathrm{mg} / \mathrm{kg} \mathrm{Al}$ was not effective $(p>0.05)$. Al induced mean average decrease of $22.2 \pm 14.8 \%, 51.9 \pm 20.8 \%, 63 \pm 13.1 \%$ and $63 \pm 13.1 \%$ at doses of $0.125,0.25,0.5$ and $1 \mathrm{mg} / \mathrm{kg}$ respectively. Like in males, 

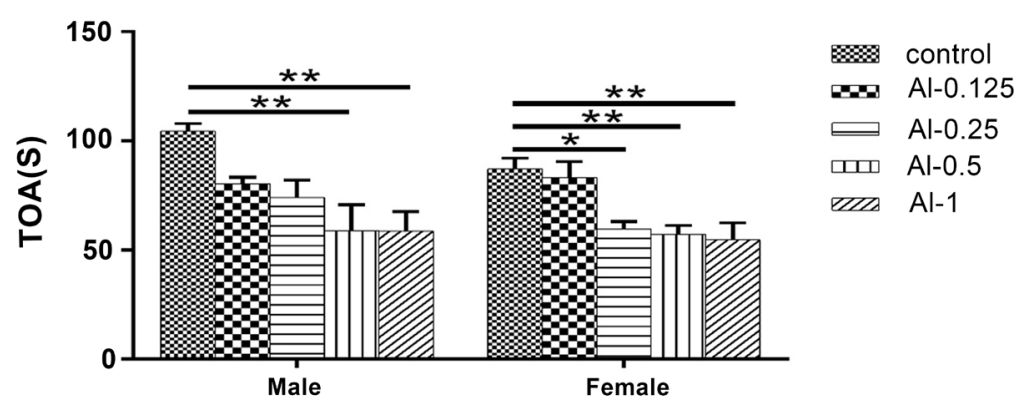

(a)

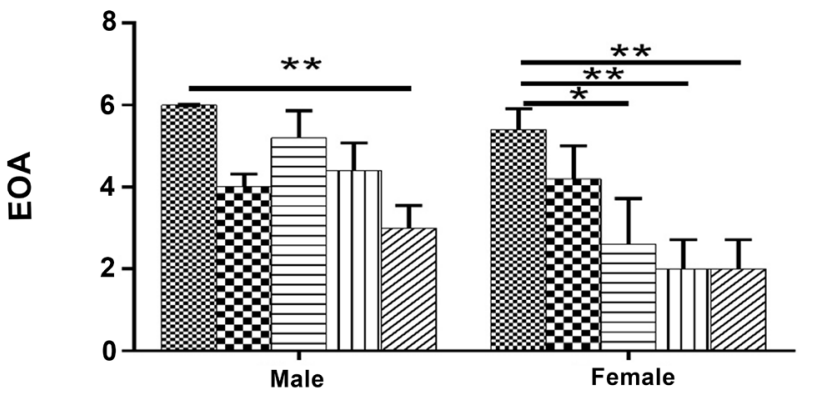
88 control
$0 \mathrm{Al}-0.125$
בAl-0.25
III) Al-0.5
11/. Al-1

(b)
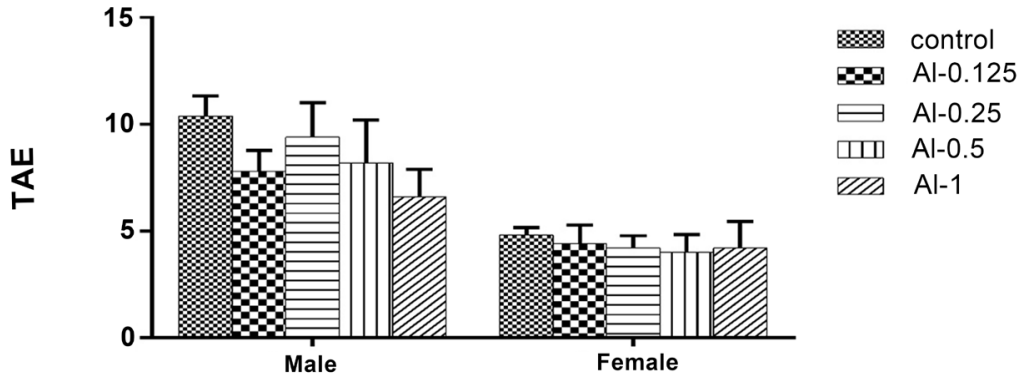

(c)

Figure 2. (a) Number of entries in exposed arms (EOA); (b) Total amount of time spent in exposed arms (TOA) and (c) Total number of arms entries (TEA) in EPM by rats after 8 weeks of treatment with different doses of Al. Results are expressed as mean \pm SEM. The significance level is $0.05 .{ }^{\star} p<0.05,{ }^{* *} p<0.01,{ }^{* *} p<0.001$.

no significant difference was observed with comparing different treated $\mathrm{Al}$ groups $(p>0.05)$ in females.

The sex effect was visible when considering the relative comparison (EOA\% $\mathrm{BL}$ ) between respective treated $\mathrm{Al}$ groups in males and females. Indeed, the males showed a EOA significantly lower compared to females of similar groups at the doses of 0.25 and $0.5(p<0.05)$.

3) Total entries in arms (TEA) (Figure 2(c)):

In contrast to TOA and EOA parameters, no effect of sex and Al treatment was found indicating lack of effect on locomotors activity (TEA) presented in Figure 2(c). Even though it is not significant, we observed a slight decrease in the total activity of females compared to males. Similar results were observed when considering the relative comparison (TAE \% BL) between treated $\mathrm{Al}$ and control groups. Thus, $\mathrm{Al}$ induced mean average decrease of $25 \% \pm 9.3 \%, 9.6 \% \pm$ 
$15.4 \%, 21.2 \% \pm 19.3 \%$ and $36.5 \% \pm 12.4 \%$ in males; of $8.3 \% \pm 18.2 \%, 12.5 \% \pm$ $12.1 \%, 16.7 \% \pm 17.4 \%$ and $12.5 \% \pm 25.9 \%$ in females respectively at doses of $0.125,0.25,0.5$ and $1 \mathrm{mg} / \mathrm{kg}$.

\subsection{Effect of Aluminum on Depressive-Like Performances Measured by Forced Swimming Test (FST)}

\section{1) Immobility Time (TIM) (Figure $3(\mathrm{a})$ ):}

This parameter presented in Figure 3(a) was affected by Al treatment ( $p<$ 0.001). In males, $\mathrm{Al}$ affects TIM parameter in dose dependent manner, between 0.125 and $1 \mathrm{mg} / \mathrm{kg}$. The difference between control and Al-1 is highly significant (cont/Al-1: $p<0.001$ ), whereas $\mathrm{Al}$ at the doses of $0.125,0.25$ and $0.5 \mathrm{mg} / \mathrm{kg}$ was not effective $(p>0.05)$. Al induced mean average increase of $18.2 \% \pm 42.2 \%$, $145.5 \% \pm 23.2 \%, 118.2 \% \pm 39.1 \%$ and $336.4 \% \pm 46.8 \%$ at doses of $0.125,0.25,0.5$ and $1 \mathrm{mg} / \mathrm{kg}$ respectively. In addition, there is a highly significant difference between Al-0.125/Al-1 $(p<0.001)$, Al-0.5/Al-1 $(p<0.01)$ and between Al-0.25/Al-1 groups $(p<0.05)$. In contrast, no difference was noted between Al-0.125/Al-0.25 and Al-0.25/Al-0.5 groups ( $p>0.05)$. Like in males, in females, A1 increases the TIM parameter in dose-dependent manner between 0.125 and $1 \mathrm{mg} / \mathrm{kg}$. While at doses of 0.125 and $0.25 \mathrm{mg} / \mathrm{kg}$ this metal did not induce any significant change in this parameter $(p>0.05), \mathrm{Al}$ significantly increases TIM at the doses of 0.5 and $1 \mathrm{mg} / \mathrm{kg}$ (cont/Al-0.5 and cont/Al-0.5: $p<0.05$ ). Al induced mean average increase of $38.1 \% \pm 34.8 \%, 76.2 \% \pm 19.3 \%, 138.1 \% \pm 32.8 \%$ and $128.6 \% \pm 16.1 \%$ at doses of $0.125,0.25,0.5$ and $1 \mathrm{mg} / \mathrm{kg}$ respectively. No significant difference was observed between different $\mathrm{Al}$ treated groups $(p>0.05)$.

The sex effect was clear when considering the relative comparison (TIM\% BL) between respective treated $\mathrm{Al}$ groups in males and females. Indeed, the male of group Al-1 showed a TIM significantly higher compared to female $(p<0.001)$.

2) Struggling Time (TST) (Figure 3(b)):

Statistical analysis showed that TST presented in Figure 3(b) was significantly affected by $\mathrm{Al}$ treatment $(p<0.001)$.

In males, The TST parameter is affected by $\mathrm{Al}$ treatment. it will be noted that $\mathrm{Al}$ decreased TST in all treated groups, but the significance was only observed in rats treated with 0,5 and $1 \mathrm{mg} / \mathrm{kg}$ compared to the control (Cont/Al-0.5: $p<0.05$ and Cont/Al-1: $p<0.001)$. Al induced mean average decrease of $13 \% \pm 2.2 \%$, $9.7 \% \pm 3.3 \%, 17 \% \pm 2.7 \%$ and $25.7 \% \pm 3.9 \%$ at doses of $0.125,0.25,0.5$ and 1 $\mathrm{mg} / \mathrm{kg}$ respectively. No significant difference was observed between different $\mathrm{Al}$ treated groups $(p>0.05)$.

The dose-dependent effect of $\mathrm{Al}$ is observed in females with referring to TST parameter. At doses of 0.5 and $1 \mathrm{mg} / \mathrm{kg}$, Al decreases the TST compared with the control (Cont/Al-0.5: $p<0.01$ and Cont/Al-1: $p<0.001$ ). Whereas $\mathrm{Al}$ at doses of 0.125 and $0.25 \mathrm{mg} / \mathrm{kg}$ still ineffective. $\mathrm{Al}$ induced mean average decrease of $3.8 \%$ $\pm 5.1 \%, 9.4 \% \pm 6.6 \%, 31.5 \% \pm 4.8 \%$ and $46.4 \% \pm 2.2 \%$ at doses of $0.125,0.25,0.5$ and $1 \mathrm{mg} / \mathrm{kg}$ respectively. In addition, there is a significant difference between Al-0.125/Al-1 and Al-0.25/Al-1 $(p<0.001)$, between Al-0.125/Al-0.5 $(p<0.01)$ 


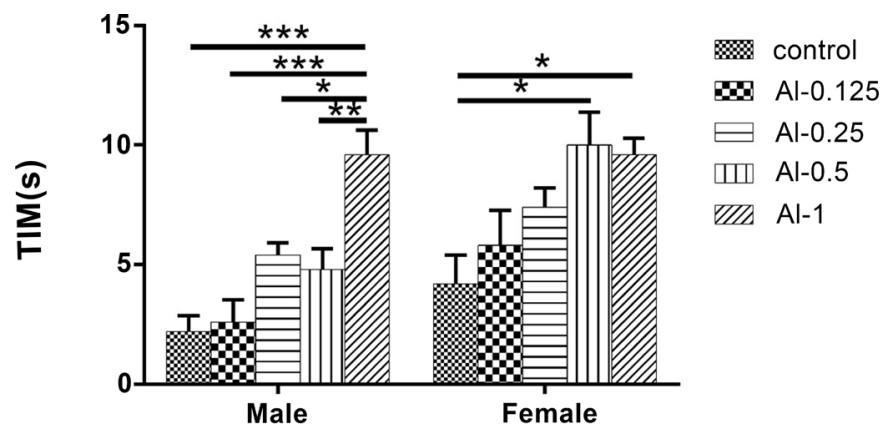

(a)

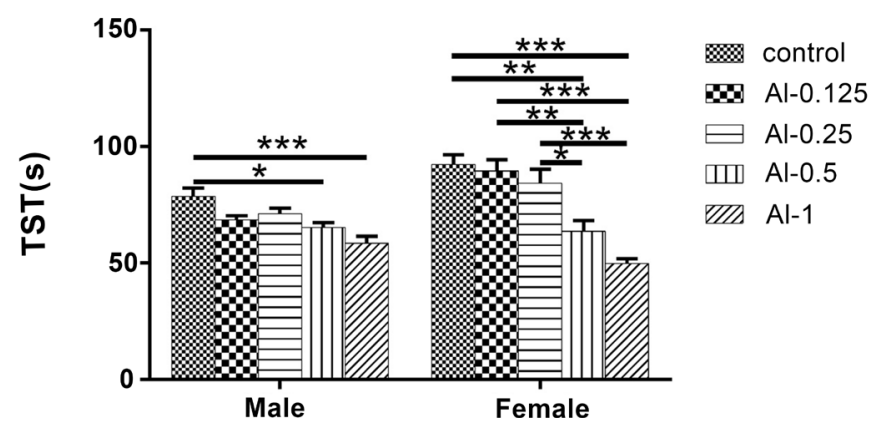

(b)

Figure 3. (a) Immobility time expressed in seconds (s) (TIM); (b) Struggling time expressed in seconds (s) in FST by rats after 8 weeks of treatment with different doses of Al. Results are expressed as mean \pm SEM. The significance level is $0.05 .{ }^{\star} p<0.05,{ }^{\star *} p<0.01$, ${ }^{* * *} p<0.001$.

and between Al-0.25/Al-0.5 $(p<0.05)$. In contrast, no difference was noted between Al-0.125/Al-0.25 and Al-0.5/Al-1 groups ( $p>0.05)$.

The sex effect was observed when considering the relative comparison (TST\% $\mathrm{BL})$ between respective treated $\mathrm{Al}$ groups in males and females. Indeed, the females of the groups Al-0.5 and Al-1 showed a TST significantly lower compared to males of similar group $(p<0.01$ and $p<0.001)$.

\subsection{Aluminum Effect on Memory}

1) Y-Maze Test (Figure 4)

Figure 4 shows that the spontaneous alternation percentage was affected by Al treatment $(p<0.01)$, but not by sex factor $(p>0.05)$.

In males and females, chronic treatment with $\mathrm{Al}$ at dose of $1 \mathrm{mg} / \mathrm{kg}$ induced significant decrease of spontaneous alternation percentage compared to the control (Cont/Al-1: $p<0.05$ ), while at doses of $0.125,0.25$ and $0.5 \mathrm{mg} / \mathrm{kg}$ this metal did not induce any significant change in this parameter $(p>0.05)$. Also, no significant difference was observed between Al treated groups $(p>0.05)$.

2) Object Recognition Test (Figure 5)

Figure 5 shows that the treatment factor significantly affected the RI (recognition index $)(p<0.001)$. In males and females, the $\mathrm{RI}$ in the training session is almost identical in Al treated groups. Even though it is not significant, we observed a slight decrease in RI parameter in females compared to males. 


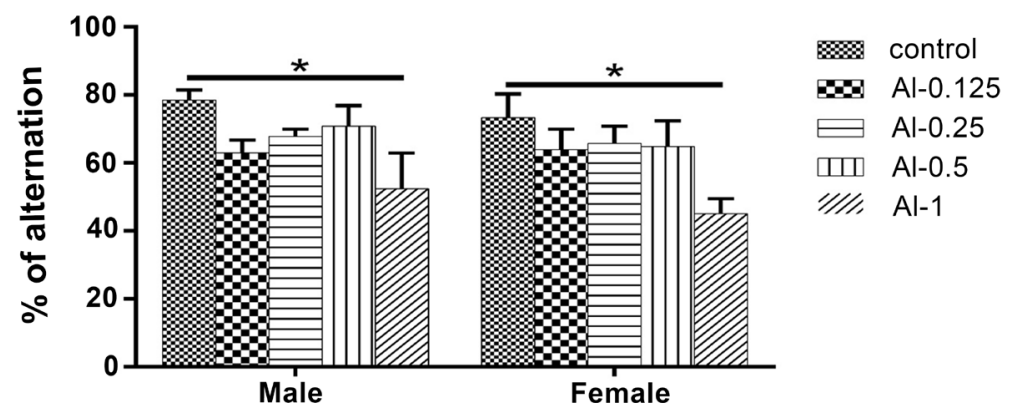

Figure 4. Spontaneous alternation percentage measured in Y-maze test in rats after 8 weeks of treatment with different doses of Al. Results are expressed as mean \pm SEM. The significance level is $0.05 .{ }^{\star} p<0.05,{ }^{\star *} p<0.01,{ }^{\star *} p<0.001$.

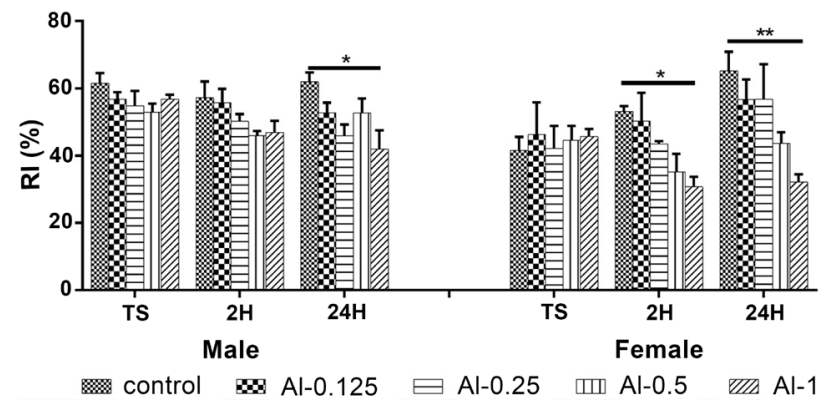

Figure 5. Recognition performances are measured in object recognition test in rats after 8 weeks of treatment with different doses of Al. Results are expressed as mean \pm SEM. The significance level is $0.05 .{ }^{\star} p<0.05,{ }^{\star *} p<0.01,{ }^{\star * \star} p<0.001$.

In males, after 2 hours of the training session, the RI parameter decreases in $\mathrm{Al}$ treated groups compared to the control, especially at Al-0.5 and Al-1 groups, but the difference was not statistically significant. In the last test session, at dose of $1 \mathrm{mg} / \mathrm{kg}$, the RI parameter decreases compared to the control (Cont/Al-1: $p<$ $0.05)$. Whereas at the doses of $0.125,0.25$ and $0.5 \mathrm{mg} / \mathrm{kg}$ we observed a slight decrease but $\mathrm{Al}$ was not effective $(p>0.05)$.

In females $\mathrm{Al}$, in the test session affected the RI parameter in dose-dependent manner. In the test session ( $2 \mathrm{H}$ and $24 \mathrm{H}$ ), at dose of $1 \mathrm{mg} / \mathrm{kg}$, the RI parameter decreases compared to the control (Cont/Al-1: $p<0.05$ in $2 \mathrm{H}$ and Cont/Al-1: $p$ $<0.01$ in $24 \mathrm{H})$. Whereas at the doses $0.125,0.25$ and $0.5 \mathrm{mg} / \mathrm{kg}$ we observed a slight decrease but $\mathrm{Al}$ was not effective $(p>0.05)$.

In addition, in both sex no significant difference was observed with comparing different treated $\mathrm{Al}$ groups in the test session $(p>0.05)$.

In the $2 \mathrm{H}$ phase, $\mathrm{Al}$ induced mean average decrease of $2.6 \% \pm 7.1 \%, 12.3 \% \pm$ $3.7 \%, 19.6 \% \pm 2.3 \%$ and $18.1 \% \pm 6.1 \%$ in males; of $12.2 \% \pm 8.2 \%, 24 \% \pm 1.4 \%$, $38.6 \% \pm 9.4 \%$ and $46.2 \% \pm 5 \%$ in females. In the $24 \mathrm{H}$ phase, $\mathrm{Al}$ induced mean average decrease of $14.8 \% \pm 4.7 \%, 25.9 \% \pm 5.5 \%, 15.1 \% \pm 7.1 \%$ and $32.3 \% \pm$ $8.9 \%$ in males; of $1 \% \pm 10.4 \%, 0.8 \% \pm 18.1 \%, 23.8 \% \pm 5.8 \%$ and $43.7 \% \pm 3.8 \%$ in females respectively at doses of $0.125,0.25,0.5$ and $1 \mathrm{mg} / \mathrm{kg}$.

The sex effect was observed when considering the relative comparison (RI \% $\mathrm{BL}$ ) between respective treated $\mathrm{Al}$ groups in males and females. Indeed, in the 
females of the groups Al-0.5 and Al- 1 in the $2 \mathrm{H}$ phase showed a RI significantly lower compared to males of similar groups ( $p<0.05$ and $p<0.05$ ), also in the $24 \mathrm{H}$ phase the $\mathrm{RI}$ in the $\mathrm{Al}-0.25$ male group is significantly lower compared to female of similar group $(p<0.05)$.

\subsection{Morris Water Maze}

\section{1) Acquisition phase (Figure 6)}

Figure 6 shows that during acquisition phase, the latency to reach the hidden platform on each of the 4 days is affected by the treatment factor.

In males, at doses of $0.25,0.5$ and $1 \mathrm{mg} / \mathrm{kg}, \mathrm{Al}$ decreases the latency to reach the hidden platform compared with the control (Cont/Al-0.25: $p<0.05$, Cont/Al-0.5: $p<0.05$ and Cont/Al-1: $p<0.01)$. In contrast any effect was observed at the dose of $0.125 \mathrm{mg} / \mathrm{kg}$.

In females, $\mathrm{Al}$ affects significantly this parameter only at dose of $1 \mathrm{mg} / \mathrm{kg}$ compared with the control (Cont/Al-1: $p<0.05$ ). All other doses are infective.

In both sex, no significant difference was observed with comparing different Al treated groups $(p<0.05)$.

2) Percentage time spent in the correct quadrant during the probe trial (Figure 7)

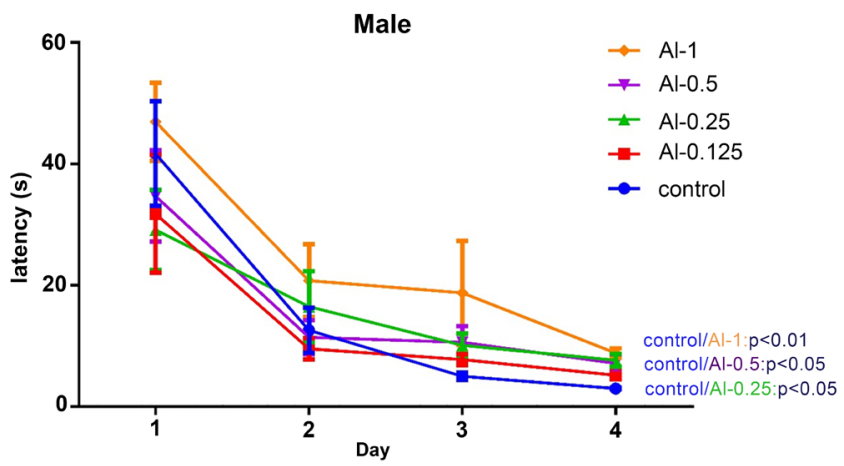

(a)

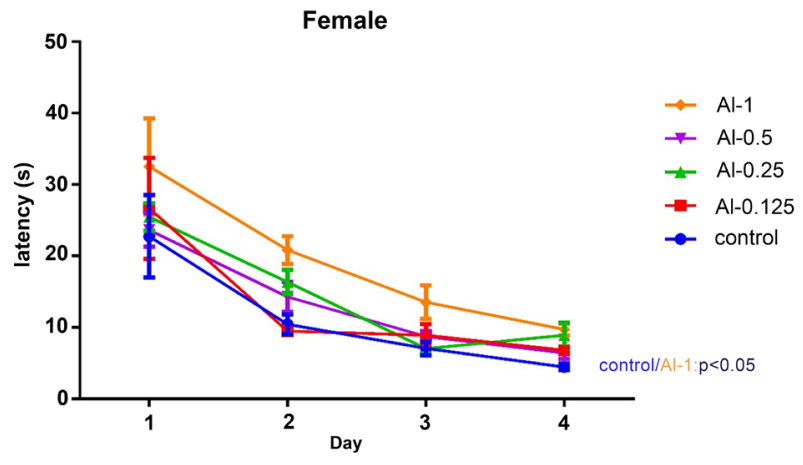

(b)

Figure 6. Latency to reach the hidden platform on each of the 4 days of training in the MWM, in male (a) and female rats (b) after 8 weeks of treatment with different doses of Al. Results are expressed as mean \pm SEM. The significance level is 0.05 . ${ }^{\star} p<0.05,{ }^{\star *} p<$ $0.01,{ }^{* * *} p<0.001$. 
The percentage of time spent in the correct quadrant presented in Figure 7 was significantly affected by Al treatment $(p<0.001)$, but not by sex factor $(p>$ 0.05).

In males, at dose of 0.25 and $1 \mathrm{mg} / \mathrm{kg}$, Al decrease the percentage of time spent in the correct quadrant with significant difference compared to the control (Cont/Al-0.25: $p<0.05$ and Cont/Al-1: $p<0.05)$. In addition, there is a significant difference between Al-0.125/Al-1 $(p<0.001)$, Al-0.25/Al-1 $(p<0.001)$ and Al-0.125/Al-0.25 $(p<0.05)$. In contrast, no difference was noted between $\mathrm{Al}-0.25 / \mathrm{Al}-0.5$ and Al-0.5/Al-1 groups ( $p>0.05)$.

In females, at dose of $1 \mathrm{mg} / \mathrm{kg}, \mathrm{Al}$ decreases this parameter compared to the control (Cont/Al-1: $p<0.05$ ). No difference was observed with comparing all $\mathrm{Al}$ treated groups $(p>0.05)$.

\section{2) Visible platform test (Figure 8)}

Latency to find the visible platform presented in Figure 8 was affected by $\mathrm{Al}$ treatment $(p<0.001)$, but not by sex factor $(p>0.05)$.

In males, $\mathrm{Al}$ affected the latency to find the visible platform. At the doses of 0.5 and $1 \mathrm{mg} / \mathrm{kg} \mathrm{Al}$ significantly increases this parameter compared with the control (Cont/Al-0.5: $p<0.05$ and Cont/Al-1: $p<0.01$ ). In addition, there is a difference between Al-0.125/Al-1 $(p<0.05)$. In contrast, no difference was noted between the other groups $(p>0.05)$

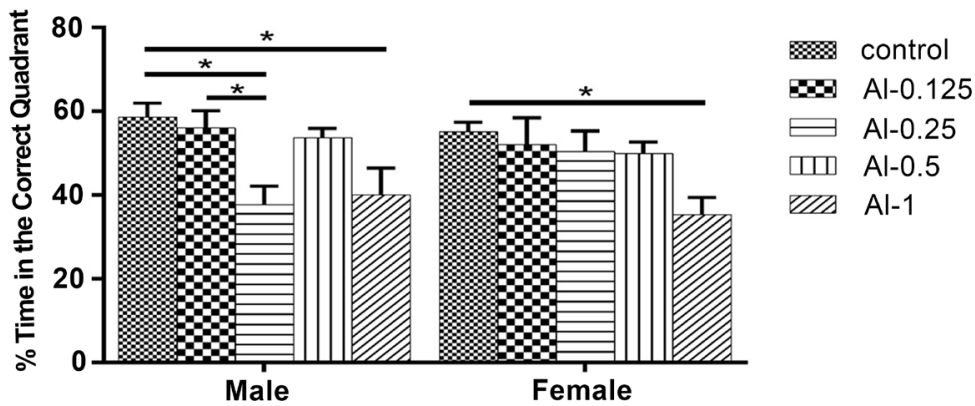

Figure 7. Percentage of time spent in the correct quadrant in the probe trial of the MWM expressed as \% in rats after 8 weeks of treatment with different doses of Al. Results are expressed as mean \pm SEM. The significance level is $0.05 .{ }^{*} p<0.05,{ }^{\star *} p<0.01,{ }^{* *} p<$ 0.001 .

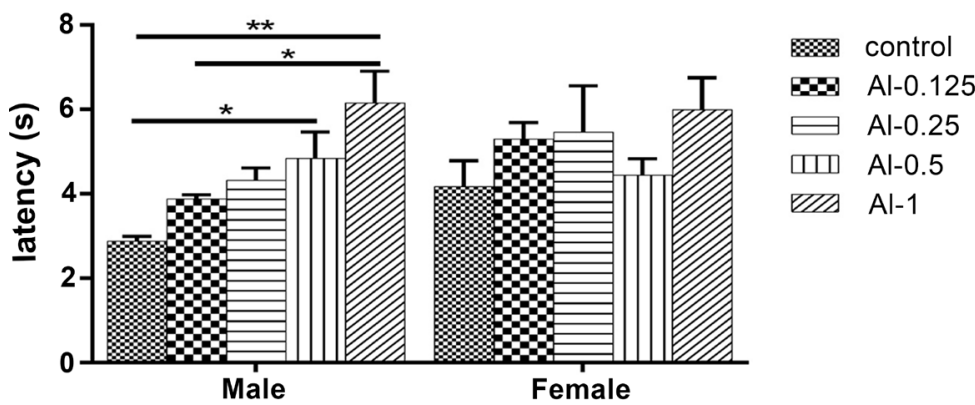

Figure 8. Latency to reach the visible platform for each strain in the MWM expressed in second (S), by rats after 8 weeks of treatment with different doses of Al. Results are expressed as mean \pm SEM. The significance level is $0.05 .{ }^{*} p<0.05,{ }^{* *} p<0.01,{ }^{* * *} p<0.001$. 
In females, the parameter was unaffected by any treatment, the values of all groups were comparable.

\section{Discussion}

The main objective of this study was to determine the effects of chronic exposure to $\mathrm{Al}$ on animal affective and cognitive disorders. The assessments of spatial learning and memory have been evaluated using respectively the Y-maze test, the ORT and the MWM tests, while anxiety-like and depression-like behaviors are based on the use of validated OFT, EPM and FST behavioral tests.

The results obtained show that $\mathrm{Al}$ administered chronically exerts an anxiogenic effect in rats; $\mathrm{Al}$ decreases the TCA and NRC parameters in the OFT and TOA and EOA parameters in EPM without modifying the locomotor activity. In two tests, anxiogenic action starts at $0.25 \mathrm{mg} / \mathrm{kg}$ and reaches a maximum at 1 $\mathrm{mg} / \mathrm{kg}$. It should be noted that at $0.125 \mathrm{mg} / \mathrm{kg}$, Al did not alter deferent parameters. The anxiogenic action of $\mathrm{Al}$ reported here is consistent with numerous studies focusing on the relationship between $\mathrm{Al}$ and behavior in rodents. Thus OFT parameters indicate elevated anxiety in Wistar rats was fed with $\mathrm{AlCl}_{3}$ at 50 $\mathrm{mg} / \mathrm{kg} / \mathrm{day}$ for 6 months in the drinking water [16]. In EPM, Wistar rats treated with $\mathrm{AlCl}_{3}$ (475, 950, 1425 and $1900 \mathrm{mg} / \mathrm{kg}$ through oral intubation for 8 weeks) were more anxious [17]. Adult rats treated with $10 \mathrm{mg} / \mathrm{kg} /$ day of Al lactate dissolved in distilled water, intragastrically for 12 weeks spent much more time in the closed arms of the EPM which correlated as anxiogenic behavior [18]. Also a study on adult mice showed that the Al-treated group observed a decrease of TCA and TOA parameters [19]. Paradoxically, Wister rats exposed to $\mathrm{AlCl}_{3}$ in drinking water since intra-uterine age spend most of the time in the enlightened compartment in dark/light test, a behavior typically considered as anxiolytic [20]. Compared with other studies, our work has the advantage of administering very small amounts of $\mathrm{Al}$ in a chronic way over a long period of the time and of obtaining effect at lower doses, since the Al efficiency appears from $0.25 \mathrm{mg} / \mathrm{kg}$.

Our results show that $\mathrm{Al}$ increases the TIM and decreases the TST parameters in FST reflecting a depressive effect of Al which starts at $0.125 \mathrm{mg} / \mathrm{kg}$ and reaches a maximum at $1 \mathrm{mg} / \mathrm{kg}$. The depressive behavior exercised by $\mathrm{Al}$ is conforming to studies made in other rodent species. Male Sprague Dawley rats receiving an intraperitoneal injection of $70 \mathrm{mg} / \mathrm{kg}$ of $\mathrm{Al}$ for 5 weeks and C57BL/6 female mice treated with $\mathrm{Al}$ (intramuscularly) for 3 months and 6 months were able to increase TIM parameter confirming the depressive effect of $\mathrm{Al}$ [21] [22].

The mechanisms by which $\mathrm{Al}$ induces these behavioral changes in animals are not yet known. Al easily accesses to the CNS via the BBB and forms a stable complex with L-glutamic acid and accumulates in different regions particularly in the striatum, hippocampus and cortex causing neuronal and glial disorders [23]. Exposure to $\mathrm{Al}$ might include changes in the levels of serotonin, noradrenaline, GABA, dopamine and glutamate [24] [25]. A drastic decrease of norepinephrine levels in the striatum, cerebral cortex and hippocampus and dopamine 
level in striatum and an elevation of glutamate and GABA levels in different brain regions have been reported [26]. As depression is a condition that is linked to hypofunction of the central serotonergic system, the serotonin level was reported to be reduced [27] in cortex, hippocampus, striatum and spinal cord brain regions of rat pups orally intubated with $\mathrm{AlCl}_{3}$. An evident diminution in serotonin in cortex, hippocampus and cerebellum after 60 days of exposure was also reported [28].

Our results show that the $\mathrm{Al}$ causes cognitive disorders characterized by affection of 1) the working memory which is due to the decrease of percentage of alternations (Y-Maze test), 2) a declarative memory following the decrease of the recognition percentage (ORT) and 3) spatial learning performance causing a deficit in spatial memory retention (MWM test). This is in agreement with different studies on memory disorders showing that $\mathrm{Al}$ causes cognitive dysfunction and negatively affects spatial learning and memory capacities of rats [16]. The same results were obtained on albino mice treated with $\mathrm{AlCl}_{3}$ for 3 months at a dose of $50 \mathrm{mg} / \mathrm{kg} /$ day [29]. In addition, exposure to very low oral doses of lactate of $\mathrm{Al}$ for 120 days altered spatial learning and memory in transgenic mice (Tg 2576) of Alzheimer's disease [30].

One of the most important mechanisms behind $\mathrm{Al}$ induced neurotoxicity has been attributed to oxidative stress [31]. The relationship between oxidative stress generation and the alteration of antioxidant system in rat brain is based on the observation that oxidative damage was caused by $\mathrm{Al}$ chloride exposure for 8 weeks [32]. The study showed an increase in LPO and decrease in SOD and CAT activities in cerebrum and cerebellum of pup and adult brains suggesting that $\mathrm{Al}$ has a pro-oxidant effect and acts as a neurotoxin in adult and pup rat brains. In another study, Wistar rats fed with $\mathrm{Al}$ chloride for 6 months in the drinking water inflicted oxidative stress-related damage to lipids, membrane associated proteins and SOD, GPx and GST activity suggesting that the compromised antioxidant system might be playing a crucial role in Al-induced oxidative stress [16]. In addition, male Wistar rats, administered with oral $\mathrm{Al}$ chloride for 30 days exhibited increased lipid and protein damage and alterations in antioxidant enzymes in brain [33].

It should be noted that many experimental considerations such as age, sex, strain and species, route of administration, $\mathrm{Al}$ salts, dose and period of treatment could explain the different results.

\section{References}

[1] Wills, M.R., Hewitt, C.D., Sturgill, B.C., Savory, J. and Herman, M.M. (1993) Long-Term Oral or Intravenous Aluminum Administration in Rabbits. I. Renal and Hepatic Changes. Annals of Clinical and Laboratory Science, 23, 1-16.

[2] Yokel, R.A. (2002) Brain Uptake, Retention, and Efflux of Aluminum and Manganese. Environmental Health Perspectives, 110, 699-704.

[3] Maya, S., Prakash, T., Das Madhu, K. and Goli, D. (2016) Multifaceted Effects of Aluminium in Neurodegenerative Diseases: A Review. Biomedicine \& Pharmaco- 
therapy, 83, 746-754. https://doi.org/10.1016/j.biopha.2016.07.035

[4] Quintal-Tun, F., Muñoz-Sánchez, J.A., Ramos-Díaz, A., Escamilla-Bencomo, A., Martínez-Estévez, M., Exley, C. and Hernández-Sotomayor, S.M.T. (2007) Aluminium-Induced Phospholipid Signal Transduction Pathway in Coffea arabica Suspension Cells and Its Amelioration by Silicic Acid. Journal of Inorganic Biochemistry, 101, 362-369. https://doi.org/10.1016/j.jinorgbio.2006.10.010

[5] Yellamma, K., Saraswathamma, S. and Kumari, B.N. (2010) Cholinergic System under Aluminium Toxicity in Rat Brain. Toxicology International, 17, 106-112.

[6] Kumar, V. and Gill, K.D. (2009) Aluminium Neurotoxicity: Neurobehavioural and Oxidative Aspects. Archives of Toxicology, 83, 965-978.

https://doi.org/10.1007/s00204-009-0455-6

[7] Gentsch, C., Lichtsteiner, M. and Feer, H. (1987) Open Field and Elevated Plus-Maze: A Behavioural Comparison between Spontaneously Hypertensive (SHR) and Wistar-Kyoto (WKY) Rats and the Effects of Chlordiazepoxide. Behavioural Brain Research, 25, 101-107. https://doi.org/10.1016/0166-4328(87)90003-9

[8] Naranjo-Rodriguez, E.B., Osornio, A.O., Hernandez-Avitia, E., Mendoza-Fernandez, V. and Escobar, A. (2000) Anxiolytic-Like Actions of Melatonin, 5-Metoxytryptophol, 5-Hydroxytryptophol and Benzodiazepines on a Conflict Procedure. Progress in Neuro-Psychopharmacology and Biological Psychiatry, 24, 117-129. https://doi.org/10.1016/S0278-5846(99)00075-5

[9] Porsolt, R.D., Anton, G., Blavet, N. and Jalfre, M. (1978) Behavioural Despair in Rats: A New Model Sensitive to Antidepressant Treatments. European Journal of Pharmacology, 47, 379-391. https://doi.org/10.1016/0014-2999(78)90118-8

[10] Benabid, N., Mesfioui, A. and Ouichou, A. (2008) Effects of Photoperiod Regimen on Emotional Behaviour in Two Tests for Anxiolytic Activity in Wistar Rat. Brain Research Bulletin, 75, 53-59. https://doi.org/10.1016/j.brainresbull.2007.07.016

[11] Sierksma, A.S.R., Van Den Hove, D.L.A., Pfau, F., Philippens, M., Bruno, O., Fedele, E., Ricciarelli, R., Steinbusch, H.W.M., Vanmierlo, T. and Prickaerts, J. (2014) Improvement of Spatial Memory Function in APPswe/PS1dE9 Mice after Chronic Inhibition of Phosphodiesterase Type 4D. Neuropharmacology, 77, 120-130. https://doi.org/10.1016/j.neuropharm.2013.09.015

[12] Bevins, R.A. and Besheer, J. (2006) Object Recognition in Rats and Mice: A One-Trial Non-Matching-to-Sample Learning Task to Study "Recognition Memory”. Nature Protocols, 1, 1306-1311. https://doi.org/10.1038/nprot.2006.205

[13] Morris, R. (1984) Developments of a Water-Maze Procedure for Studying Spatial Learning in the Rat. Journal of Neuroscience Methods, 11, 47-60. https://doi.org/10.1016/0165-0270(84)90007-4

[14] Wong, A.A. and Brown, R.E. (1984) Age-Related Changes in Visual Acuity, Learning and Memory in C57BL/6J and DBA/2J Mice. Neurobiology of Aging, 11, 47-60. https://doi.org/10.1016/0165-0270(84)90007-4

[15] Kahloula, K., Eddine, D., Adli, H., Slimani, M., Terras, H. and Achour, S. (2014) Effet de l'exposition chronique au nickel sur les fonctions neurocomportementales chez les rats Wistar pendant la période de développement. Toxicologie Analytique et Clinique, 26, 186-192. https://doi.org/10.1016/j.toxac.2014.09.056

[16] Sethi, P., Jyoti, A., Singh, R., Hussain, E. and Sharma, D. (2008) Aluminium-Induced Electrophysiological, Biochemical and Cognitive Modifications in the Hippocampus of Aging Rats. Neurotoxicology, 29, 1069-1079.

[17] Ojo, S.A., Hambolu, J.O., Adebisi, S.S. and Medicine, F. (2011) Effects of Aluminium Chloride on Anxiety-Related Behaviour. Department of Human Anatomy, Department 
of Veterinary Anatomy, Faculty of Veterinary Medicine, Ahmadu Bello University, Zaria, 2, 65-69.

[18] Sharma, D.R., Wani, W.Y., Sunkaria, A., Kandimalla, R.J.L., Verma, D., Cameotra, S.S. and Gill, K.D. (2013) Quercetin Protects against Chronic Aluminum-Induced Oxidative Stress and Ensuing Biochemical, Cholinergic, and Neurobehavioral Impairments in Rats. Neurotoxicity Research, 23, 336-357.

[19] Bannon, D. (2015) The Behavioural Effects of Stress and Aluminium Toxicity on a Mouse Model of Amyotrophic Lateral Sclerosis Parkinsonism-Dementia Complex. https://open.library.ubc.ca/collections/24/items/1.0166354

[20] Erazi, H., Sansar, W., Ahboucha, S. and Gamrani, H. (2010) Aluminum Affects Glial System and Behavior of Rats. Comptes Rendus Biologies, 333, 23-27. https://doi.org/10.1016/j.crvi.2009.09.016

[21] Ali, A.A., Ahmed, H.I., El-samea, H.A.A. and El-demerdash, E. (2016) The Potential Effect of Caffeine and Nicotine Co-Administration against Aluminum-Induced Alzheimer's Disease in Rats. Journal of Alzheimer's Disease \& Parkinsonism, 6, 236.

[22] Inbar, R., Weiss, R., Tomljenovic, L., Arango, M.-T., Deri, Y., Shaw, C.A., Chapman, J., Blank, M. and Shoenfeld, Y. (2017) Behavioral Abnormalities in Female Mice Following Administration of Aluminum Adjuvants and the Human Papillomavirus (HPV) Vaccine Gardasil. Immunologic Research, 65, 136-149. https://doi.org/10.1007/s12026-016-8826-6

[23] Deloncle, R., Guillard, O., Huguet, F. and Clanet, F. (1995) Modification of the Blood-Brain Barrier through Chronic Intoxication by Aluminum Glutamate-Possible Role in the Etiology of Alzheimer's Disease. Biological Trace Element Research, 47, 227-233. https://doi.org/10.1007/BF02790121

[24] Wenk, G. and Stemmer, K. (1981) The Influence of Ingested Aluminum upon Norepinephrine and Dopamine Levels in the Rat Brain. Neurotoxicology, 2, 347-353.

[25] Beal, M., Mazurek, M., Ellison, D. and Kowall, N. (1989) Neurochemical Characteristics of Aluminum-Induced Neurofibrillary Degeneration in Rabbits. Neuroscience, 29, 339-346. https://doi.org/10.1016/0306-4522(89)90061-4

[26] Gonçalves, P.P. and Silva, V.S. (2007) Does Neurotransmission Impairment Accompany Aluminium Neurotoxicity? Journal of Inorganic Biochemistry, 101, 1291-1338. https://doi.org/10.1016/j.jinorgbio.2007.06.002

[27] Ravi, S.M., Prabhu, B.M., Raju, T.R. and Bindu, P.N. (2000) Long-Term Effects of Postnatal Aluminium Exposure on Acetylcholinesterase Activity and Biogenic Amine Neurotransmitters in Rat Brain. Indian Journal of Physiology and Pharmacology, 44, 473-478.

[28] Kumar, S. (2002) Aluminium-Induced Changes in the Rat Brain Serotonin System. Food and Chemical Toxicology, 40, 1875-1880.

[29] Rebai, O. and Djebli, N.E. (2008) Chronic Exposure to Aluminum Chloride in Mice: Exploratory Behaviors and Spatial Learning. Journal of Biological Research, 2, 26-33.

[30] Ribes, D., Colomina, M.T., Vicens, P. and Domingo, J.L. (2008) Effects of Oral Aluminum Exposure on Behavior and Neurogenesis in a Transgenic Mouse Model of Alzheimer's Disease. Experimental Neurology, 214, 293-300.

[31] Naidu, N.R., Bhat, S. and Dsouza, U. (2013) Effect of Long Term Administration of Aluminum Chloride on Oxidative Stress and Acetylcholinesterase Activity in Rat Brains. IJPBS, 3, 616-622.

[32] Nehru, B. and Anand, P. (2005) Oxidative Damage Following Chronic Aluminium 
Exposure in Adult and Pup Rat Brains. Journal of Trace Elements in Medicine and Biology, 19, 203-208. https://doi.org/10.1016/j.jtemb.2005.09.004

[33] Jyoti, A., Sethi, P. and Sharma, D. (2007) Bacopa monniera Prevents from Aluminium Neurotoxicity in the Cerebral Cortex of Rat Brain. Journal of Ethnopharmacology, 111, 56-62. 